\section{Living with diabetes: Life story with a difference}

\section{BRIEF BACKGROUND}

Nishant (name changed) lives in a suburb of Karnal, where his parents migrated 6 years ago in search of livelihood. The family lives in rented accommodation and does not enjoy the social support that the traditional Haryanvi village or extended family offers. While Nishant's father works in a leather factory, his mother manages the home and her 2-year-old daughter. The family is barely able to make both ends meet, and often has to borrow money from the local moneylender at high-interest rates, to meet medical expenses.

\section{WHEN AND HOW THE FAMILY CAME TO KNOW ABOUT NISHANT'S TYPE 1 DIABETES}

Nishant was diagnosed to have Type 1 diabetes at the age of 36 months when he suddenly fell ill. Various healthcare providers were unable to diagnose his ailment until a pediatrician ordered a routine urine test which revealed high levels of sugar and ketones. The pediatrician referred Nishant to the medical college in the state capital, where he was diagnosed and treated as a case of diabetic ketoacidosis. Nishant was admitted in hospital for 7 days and discharged with a label of 1 diabetes. However, the parents were ill-equipped to manage diabetes in such a small child on their own.

\section{INITIAL REACTIONS OF FAMILY}

The family of Nishant took a long time to understand what was happening. The days at the medical college passed in a daze, with both parents busy trying to arrange the money, material, and medicines needed for Nishant. They hardly had time to think about the implications of the condition. It was only when they reached home that the realization of the disease dawned upon them.

The parents felt that Nishant had been cursed with a lifelong sentence because of sins incurred in the previous lives. His mother thought that it was her own sins which were visited upon her innocent son. The paternal grandmother, who resides in a remote village of a neighboring district, declared that it was a contagious disease contracted from maternal blood, and forbade her son from having any relations with his wife. Nishant's father, who had been a social drinker till now, was unable to handle all the stress and turned to alcohol to dilute his sorrows.

All in all, the diagnosis of diabetes affected the family as much as it affected Nishant. Nishant's parents were unable to inject insulin, so they would take him to a nearby chemist twice a day for premixed insulin injections. The chemist charged Rs. 5/- for each injection, adding to the financial burden of the disease.

\section{ISSUES AND BELIEFS}

The first few weeks of managing diabetes at home were like hell for Nishant's parents. One day, they attended a prayer meeting conducted in their locality. The preacher was a learned woman who spoke about the importance of protecting and preserving one's body, as it is the temple of one's soul. She also clarified that illness is not the result of previous sins, as God loves all his children, and does not want to punish anyone. The preacher stated that illness occurs because of imbalance in body salts and can easily be managed with the help of modern medicines. Nishant's parents were motivated by this sermon and began to think about how to manage Nishant's diabetes proactively.

\section{JOURNEY OF LIVING AND LEARNING to MAnage Diabetes for the ChILD}

At about this time, the chemist noticed a gradual deterioration in Nishant's health status. He referred them to the local endocrinology center. The parents were very anxious and worried when they came to the hospital, as they had been told it was a very expensive facility. They had already spent tens of thousands of rupees at the government institute. How much more would they have to shell out?

A pleasant surprise awaited them at the endocrine clinic. They were directed to the Changing Diabetes in Children $(\mathrm{CDiC})$ clinic, ${ }^{[1]}$ which was actively registering children at that time. Meenakshi and Mani, the $\mathrm{CDiC}$ coordinators, immediately took charge of Nishant. Playfully, they were able to take his height and weight measurements, check his injection sites, and point out lipohypertrophic patches to his parents. Nishant got a new toy, the Mishti 
doll, to hug and play with. ${ }^{[2]}$ The parents were amazed: they had never expected or anticipated such a friendly atmosphere in a health-care facility. Nishant left the $\mathrm{CDiC}$ clinic with a smile, clutching his new friend Mishti, and carrying a bag full of insulin, insulin syringes, and educational material.

Over frequent visits, the parents learned how to inject insulin, monitor blood glucose, watch for hypoglycemia and manage it, plan healthy meals, and motivate Nishant to play games regularly. ${ }^{[3]}$ They also understood that both child and family have to live with diabetes. While they do not have a choice in this regard, they can certainly choose whether to live a happy and healthy life with diabetes or not. This choice is the family's, not the treating physician's.

\section{INCIDENT WHICH DOCTOR WISHES TO SHARE}

In the initial months of care, Nishant would often come to the clinic with high glucose values. Upon questioning, the parents would admit that they had skipped insulin because relatives had come to visit them, and they were shy of injecting Nishant in front of others. It was explained to them that insulin is not a stigma. In fact, insulin is a lifesaver for which one should be grateful.

Once they realized this, Nishant's parents began injecting him even in the presence of visiting relatives and friends. Initially, they had to face comments such as "bechara" and "poor little boy," and answer hurtful questions such as "how long will he live" or "will he be able to marry?" With time, the extended family has become used to insulin being a part of Nishant's life.

Nishant explains to his relatives that insulin is his buddy and is just like wearing spectacles or eating food for him. He once told his grandmother: "You eat onions which make you cry; I take insulin which makes me smile."

\section{ENVIRONMENTAL FACTORS INFLUENCING CHILD'S LIFE}

\section{Family}

Nishant now has a younger sister, whom he loves very much. The family has to take care of two children with limited resources and scarce finance. The parents also worry about the future of their children. However, they realize that diabetes is just a part of life; neither more nor less.
Friends

Most of the friends know that Nishant has diabetes. Initially, neighbors were afraid that their children would "catch" diabetes from Nishant, but now, they realize that it is a noncontagious disease. Many times, while playing, they remind him to go home as it is time for his insulin dose.

\section{School}

The teacher at school does know that Nishant has diabetes but is not equipped to help him in the case of need. Nishant carries toffees to school everyday, to take if he feels giddy, uneasy, or hungry. However, he eats it almost every day, even if he feels fine.

\section{Medical center}

Nishant is best friends with Meenakshi didi and Mani didi. He likes coming to the CDiC center. Nishant and the doctor have a special game which they always play. At the count of three, both bring out their tongue. The one with the longer tongue wins and gets a prize. Nishant is an expert at this game, he always wins the competition. He often gets little gifts such as pens and paper from the doctor. The only problem is that sometimes the doctor does not have a gift to share: this makes Nishant sad and wants to cry.

\section{$\mathrm{CDiC}$}

Nishant has gained a lot from the CDiC program, as he gets a free medical consultation, investigations, insulin, and monitoring supplies. This has helped the family save money for his education and future.

\section{Camps}

Nishant visits the CDiC clinic whenever a camp is held. $\mathrm{He}$ has won prizes in painting and poem recitation. $\mathrm{He}$ likes it when all the children clap for him.

The best part about camps, according to Nishant, is the salted buttermilk and biscuits that are served there. His wish list includes toffees, chocolates, and cake, but he knows these can harm him.

\section{DOCTOR'S INSIGHT}

Caring for Nishant has taught me much more than what the book ${ }^{[4]}$ has:

1. Diabetes is not just a medical condition; it is a syndrome with biological, psychological, and social ramifications. Thus, it requires an understanding of the biopsychosocial model of health, if one is to manage it properly.

2. Diabetes care is not a $100 \mathrm{~m}$ race, it is more like a marathon. Both family and physician must realize this 
and be prepared for it. The condition does not affect just the individual with diabetes, it involves family and community as well.

3. And when we say that diabetes is a multisystemic syndrome involving the pancreas, nerves eyes, and kidneys, we should remember that it impacts the wallet as well.

\section{IMPACT OF DIABETES ON LIFE}

Diabetes has had an impact on the family, both positive and negative. Nishant's mother is unable to work, as she needs to be at home when Nishant returns from school. Food habits have changed, and the family never goes for vacation. On the positive side, Nishant and his family have become more disciplined. His father has quit drinking and now focuses his energy on earning and saving money for his children.

\section{AMBITIONS AND ASPIRATIONS}

Nishant wishes to become a wrestler and win medals so that everyone claps for him. For the time being, however, he knows that he has to go to school and study. He also knows that insulin will help him grow up to be healthy and happy.

\section{CONCLUSION}

- The real life story of Nishant helps us understand the impact of Type 1 diabetes on a family's life.

- Type 1 diabetes in a child is much more than insulin deficiency. It impacts both child and family in many ways: biological, psychological, and social.

- All these aspects need to be considered while caring for children with diabetes.

- $\mathrm{CDiC}$ helps us improve our care for children with diabetes.

Financial support and sponsorship

Nil.

\section{Conflicts of interest}

There are no conflicts of interest.

Bharti Kalra, Meenakshi Thukral

Department of Obstetrics, CDiC Project, Bharti Hospital, Karnal, Haryana, India

Corresponding Author: Dr. Bharti Kalra,

Department of Obstetrics, Bharti Hospital, Karnal, Haryana, India. E-mail: bridekarnal@gmail.com

\section{REFERENCES}

1. Kumar KM, Raghupathy P, Kalra S. Diabetes-friendly environments for children with diabetes. Indian J Endocrinol Metab 2015;19 Suppl 1:S1-3.

2. Kalra S, Chugh S, Dinakaran P. Diabetes and play therapy. J Soc Health Diabetes 2014;2:40-4.

3. Altamash S. Family therapy. Indian J Endocr Metab 2013;17 Suppl S1:292-4.

4. Kalra S, Sridhar GR, Balhara YP, Sahay RK, Bantwal G, Baruah MP, et al. National recommendations: Psychosocial management of diabetes in India. Indian J Endocrinol Metab 2013;17:376-95.

This is an open access article distributed under the terms of the Creative Commons Attribution-NonCommercial-ShareAlike 3.0 License, which allows others to remix, tweak, and build upon the work non-commercially, as long as the author is credited and the new creations are licensed under the identical terms.

\begin{tabular}{|l|l|}
\hline \multicolumn{2}{|c|}{ Access this article online } \\
\hline Quick Response Code: & Website: \\
\hline & www.joshd.net \\
\cline { 2 - 3 } & \\
\hline
\end{tabular}

How to cite this article: Kalra B, Thukral M. Living with diabetes: Life story with a difference. J Soc Health Diabetes 2017;5:56-8. 